This is a peer-reviewed, accepted author manuscript of the following article: Javadi, Y., Raeisi, M. H., Pirzaman, H. S., \& Najafabadi, M. A. (2013).

Using welding simulation and ultrasonic method to evaluate residual stress in stainless steel welded plates. In ASME 2012 11th Biennial

Conference on Engineering Systems Design and Analysis, ESDA 2012 (Vol. 1, pp. 43-50). [ESDA2012-82637] New York: ASME.

https://doi.org/10.1115/ESDA2012-82637

The ASME 2012 11th Biennial Conference On Engineering Systems Design And Analysis

ESDA2012

July 2-4, 2012, Nantes, France

ESDA2012- 82637

\title{
USING WELDING SIMULATION AND ULTRASONIC METHOD TO EVALUATE RESIDUAL STRESS IN STAINLESS STEEL WELDED PLATES
}

\author{
Yashar Javadi \\ Amirkabir University of Technology, \\ Department of Mechanical Engineering \\ Tehran, Iran \\ Hamed Salimi Pirzaman \\ Amirkabir University of Technology, \\ Department of Mechanical Engineering \\ Tehran, Iran
}

\author{
Mohammadreza Hadizadeh Raeisi \\ Amirkabir University of Technology, \\ Department of Mechanical Engineering \\ Tehran, Iran \\ Mehdi Ahmadi Najafabadi \\ Amirkabir University of Technology, \\ Department of Mechanical Engineering \\ Tehran, Iran
}

\begin{abstract}
When a material is under mechanical load, the stresses change the velocity of acoustic waves because of acoustoelastic effect. This property can be employed for stress measurement in the material itself when the stress concerns the surface of the material, or in the bulk material. This technique involves with critically refracted longitudinal waves that propagate parallel to the surface, i. e. $L_{C R}$ waves. This paper presents a three dimensional thermo-mechanical analysis to evaluate welding residual stresses in plate-plate joint of AISI stainless steel 304L. After finite element simulation, the residual stresses were evaluated by $L_{C R}$ ultrasonic waves. This paper introduces a combination of "Finite Element Welding Simulation" and "Ultrasonic Stress Measurement using the $L_{C R}$ Wave" which is called as "FEL $L_{C R}$ ". The capabilities of FEL ${ }_{C R}$ in residual stress measurement are confirmed here. It has been shown that predicted residual stress from three dimensional FE analyses is in reasonable agreement with measured residual stress from $L_{C R}$ method.
\end{abstract}

Keywords: Ultrasonic Stress Measurement; Acoustoelastic Effect; Welding Residual Stress; $L_{C R}$.

\section{INTRODUCTION}

Residual stresses are present in materials without any external pressure, and normally result from deformation heterogeneities appearing in the material. They have very important role in the strength and service life of structures. Welding is an assembly process often used in different industries, especially in the pressure vessel industry. According to the process and temperatures reached during this operation, dangerous thermomechanical stresses may appear in the welded joint. To achieve a proper design of structure and control their mechanical strength in service, it is very important to determine the residual stress levels with a non-destructive method. The high industry request for the stress measurement techniques encouraged development of several methods like X-ray diffraction, incremental hole drilling, and the ultrasonic wave methods. Many studies showed that there is no universal or absolute method that gives complete satisfaction in the non-destructive stress monitoring of the mechanical components. Many parameters such as material, geometry, surface quality, cost, and accuracy of the measurement, etc., must be taken into account in choosing an adequate technique. 
This is a peer-reviewed, accepted author manuscript of the following article: Javadi, Y., Raeisi, M. H., Pirzaman, H. S., \& Najafabadi, M. A. (2013). Using welding

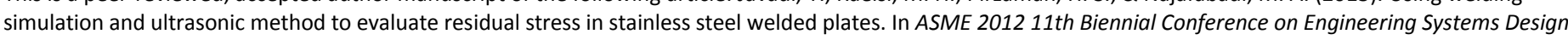
and Analysis, ESDA 2012 (Vol. 1, pp. 43-50). [ESDA2012-82637] New York: ASME. https://doi.org/10.1115/ESDA2012-82637

\section{ULTRASONIC METHOD}

The ultrasonic technique was selected for stress measurement because it is non-destructive, easy to use, and relatively inexpensive. However, it is slightly sensitive to the microstructure effects (grains size $[1,2,3]$, carbon rate $[4,5]$, texture $[6,7,8,9]$, and structure $[10,11,12])$ and to the operating conditions (temperature [13, 14], coupling [15, 16], etc.). The ultrasonic estimation of the residual stresses requires separation between the microstructure and the acoustoelastic effects.

\section{WELDING SIMULATION}

The degree of deformations and residual stresses in welded components depends on several factors such as geometrical dimension, welding parameters, welding sequence and applied structural boundary conditions. Finite element (FE) simulation has become a popular method for the prediction of welding distortions and residual stresses. Earlier studies of welding process accounted for the non-linearities due to temperature dependent material properties and plastic deformations $[17,18$, 19]. The majority of those welding analyses were limited to two-dimensional simulation on the plane perpendicular to the welding direction. Good correlations have been observed between the numerical predictions and experimental results [20, $21,22,23]$.

\section{THEORETICAL BACKGROUND}

\section{ACOUSTOELASTIC EFFECT}

Within the elastic limit, the ultrasonic stress measuring technique relies on a linear relationship between the stress and the travel time change, i.e. the acoustoelastic effect [24, 25]. The $L_{C R}$ technique uses a special longitudinal bulk wave mode, as shown in Fig. 1, which propagates parallel to the surface, particularly travelling beneath the surface at a certain depth. The $L_{C R}$ waves are also called surface skimming longitudinal waves (SSLW) by some of the authors. Brekhovskii [26], Basatskaya and Ermolov [27], Junghans and Bray [28], Langenberg et al. [29] had some detailed discussions on the characteristics of the $L_{C R}$.

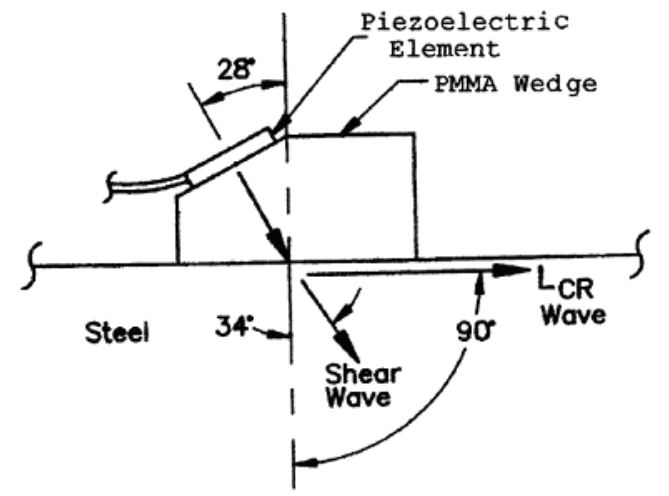

Fig. 1. LcR probe for PMMA(plexiglas) wedge on steel[30].

Ultrasonic stress measurement methods are based on the relationship of wave speed in different directions with stress. Fig. 2. shows elements of a bar under tension where the ultrasonic wave propagates in three perpendicular directions.
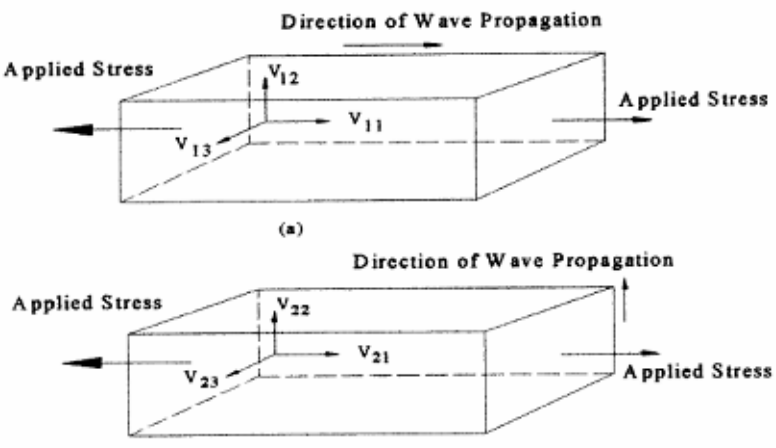

(b)

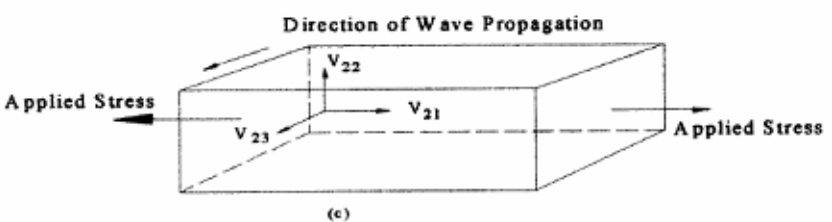

Fig. 2. Velocity of plane wave and stress field in orthogonal directions[30].

The first index in the velocities is the propagation direction for the ultrasonic wave and the second represents the direction of the movement of the particles. In Fig. 2a the wave propagates parallel to the load and $V_{l l}$ represents the velocity of the particles in the same direction (longitudinal wave), meanwhile $V_{12}$ and $V_{13}$ represents the velocity in a perpendicular plane (shear waves).

In Fig. $2 \mathrm{~b}$ and Fig. $2 \mathrm{c}$ the waves propagating in the other directions and the velocities are shown. The $V_{22}$ velocity is for longitudinal waves propagating perpendicular to the stress direction. The sensitivity of these waves to the strain has been established by Egle and Bray [24] in tensile and compressive load tests for a bar of rail steel. The waves with particle motion 
This is a peer-reviewed, accepted author manuscript of the following article: Javadi, Y., Raeisi, M. H., Pirzaman, H. S., \& Najafabadi, M. A. (2013). Using welding

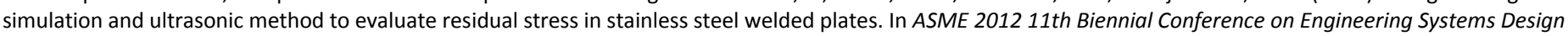
and Analysis, ESDA 2012 (Vol. 1, pp. 43-50). [ESDA2012-82637] New York: ASME. https://doi.org/10.1115/ESDA2012-82637

in the direction of the stress fields showed the maximum sensitivity to stress, and those with particle motions perpendicular to the stress field showed the minimum. The most significant variation in travel time with the strain was found for longitudinal waves, followed by the shear waves when the particles vibrate in the direction of the load. The other waves do not show important sensitivity to the strain. The velocities of the longitudinal plane waves propagating parallel to load can be related to the strain $(\alpha)$ by the following expressions:

$\rho_{0} V_{11}^{2}=\lambda+2 \mu+(2 l+\lambda) \theta+(4 m+4 \lambda+10 \mu) \alpha_{1}$

Eq.(1).

where $\rho_{\mathrm{o}}$ is the initial density; $V_{11}$ is the velocity of waves in the direction 1 with particle displacement in the direction $1 ; \lambda, \mu$ the second order elastic constants (Lame's constants); $l, m, n$ are the third order elastic constants; $\theta=\alpha_{1}+\alpha_{2}+\alpha_{3}$ which $\alpha_{1}$, $\alpha_{2}$ and $\alpha_{3}$ are components of the homogeneous triaxial principal strains. For a state of uniaxial stress, $\alpha 1=\varepsilon, \alpha 2=\alpha 3=-$ $v \times \varepsilon$, where $\varepsilon$ is the strain in the direction 1 and $v$ is the Poisson's ratio. Using these values, Eq. (1) becomes:

$$
\rho_{0} V_{11}{ }^{2}=\lambda+2 \mu+\left[4(\lambda+2 \mu)+2(\mu+2 m)+v \mu\left(1+\frac{2 \lambda}{\mu}\right)\right] . \varepsilon \quad \text { Eq.(2). }
$$

The relative sensitivity is the variation of the velocity with the strain and can be calculated by Eq. (3). In this equation, L11 is the dimensionless acoustoelastic constant for $L_{C R}$ waves.

$\frac{d V_{11} / V_{11}}{d \varepsilon}=2+\frac{(\mu+2 m)+v \mu(1+2 l / \lambda)}{\lambda+2 \mu}=L_{11}$

The values of acoustoelastic constants for the other directions can be calculated in the same way. The variation in the $v_{11}$ velocity, controlled by the coefficient $L_{11}$, is much greater than the other ones, representing that these waves are the best candidates to be used in the stress evaluation. Stress can be obtained by the one-dimensional application of the stress-strain relations in elastic solids. Equation (3) can be rearranged to give the stress variation in terms time-of-flight ( $\left.\mathrm{d} t / t_{\mathrm{o}}\right)$, as shown in the Eq. (4), where to is the time for the wave to go through a stress free path in the material being investigated.

$d \sigma=\frac{E\left(d V_{11} / V_{11}\right)}{L_{11}}=\frac{E}{L_{11} t_{0}} d t$

Where $\mathrm{d} \sigma$ is the stress variation (Mpa) and $E$ is the elasticity modulus (Mpa). The same equation can be used for the other directions of the waves, provided the value of the acoustoelastic coefficient $L$ is changed. For a fixed probe distance, the travel time of the longitudinal wave decreases in a compressive stress field and increases in a tensile field. The acoustoelastic constant $(L)$ functionally links the stress and the velocity or travel time change.

\section{FINITE ELEMENT WELDING SIMULATION}

\section{MODELING OF PHYSICAL PHENOMENA}

Numerical simulation of residual stresses due to welding need to accurately take account of the interactions between heat transfer, metallurgical transformations and mechanical fields. The process involved in the heat input such as arc, material interactions as well as fluid dynamics in the weld pool are not accurately described. From the thermo-mechanical point of view, the heat input can be seen as a volumetric or surfaced energy distribution, and the fluid flow effect, which leads to homogenize the temperature in the molten area, can be simply taken into account by rising the thermal conductivity over the fusion temperature. As no metallurgical transformation occurs in the 304L stainless steel considered in this paper, no detailed modeling of the melting is considered here. Heat transfers in solids are described by the heat equation:

$\rho \frac{d H}{d t}-\operatorname{div}(\lambda \operatorname{grad} T)-Q=0$

$\operatorname{\lambda gradT.n}=q(T, t)$ on $\quad \partial \Omega_{q}$

$T=T_{p}(t)$

on

$\partial \Omega_{t}$

Eq.(7).

Where $\rho, H, \lambda$ and $T$ are density, enthalpy, thermal conductivity and temperature, respectively. In Eq. (5), Q represents an internal heat source. In Eq. (6), $\mathrm{n}$ is the outward normal vector of domain $\delta \Omega$ and $\mathrm{q}$ the heat flux density that can depend on temperature and time to model convective heat exchanges on the surface. Tp represents a prescribed temperature. The heat input is represented by an internal heat source. In the present study, the double ellipsoid heat source configuration proposed by Goldak et al. [31] is used, as shown in Fig. 3. As it is seen, the front half of the heat source is the quadrant of one ellipsoidal source, and the rear half is the quadrant of another ellipsoid. In this model, the fractions of $\mathrm{ff}$ and $\mathrm{fr}$ of the heat deposited in the front and rear quadrants are needed, where $\mathrm{ff}+\mathrm{fr}=2$.

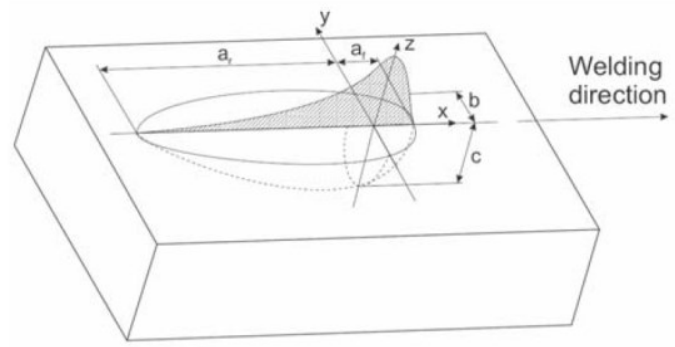

Fig. 3. Double ellipsoid heat source configuration [31].

The power density distribution inside the front quadrant is:

$q_{f}(x, y, z)=\frac{6 \sqrt{3} f_{f} Q}{a_{f} b c \pi^{3 / 2}} e^{\left(-3 x^{2} / a_{f}^{2}\right)} e^{\left(-3 y^{2} / b^{2}\right)} e^{\left(-3 z^{2} / c^{2}\right)}$

Similarly, for the rear quadrant of the source the power density distribution inside the ellipsoid becomes: 
This is a peer-reviewed, accepted author manuscript of the following article: Javadi, Y., Raeisi, M. H., Pirzaman, H. S., \& Najafabadi, M. A. (2013). Using welding

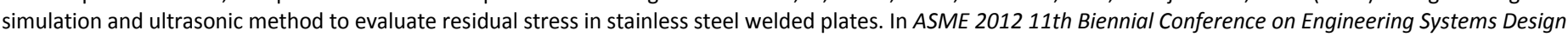
and Analysis, ESDA 2012 (Vol. 1, pp. 43-50). [ESDA2012-82637] New York: ASME. https://doi.org/10.1115/ESDA2012-82637

$q_{r}(x, y, z)=\frac{6 \sqrt{3} f_{r} Q}{a_{r} b c \pi^{3 / 2}} e^{\left(-3 x^{2} / a_{r}{ }^{2}\right)} e^{\left(-3 y^{2} / b^{2}\right)} e^{\left(-3 z^{2} / c^{2}\right)}$

Physically these parameters are the radial dimensions of the molten zone in front, behind, to the side, and underneath the arc. If the cross-section of the molten zone is known from the experiment, these data may be used to fix the heat source dimensions. If cross-sectional dimensions are not available, the experience data given by Goldak et al. [31] suggest that it is reasonable to take the distance in front of the heat source equal to one-half the weld width and the distance behind the heat source equal to twice the width. These suggestions are used in this paper. The internal heating due to the plastic dissipation can be neglected considering the small transformation rates generated by a welding process.

The mechanical analysis is based on the ordinary equations describing the static equilibrium. As the plastic dissipation is neglected in the thermal analysis, thermal and mechanical analyses can be treated separately. Thus, the mechanical calculation is achieved using the temperature fields computed previously by the thermal analysis. The materials are supposed to follow an elastic-plastic behavior with isotropic hardening. The material parameters Young's modulus, Poisson's ratio, yield stress, strain hardening and heat expansion coefficient are temperature dependent.

\section{MATERIAL MODELING}

Material modeling has always been a serious issue in the simulation of welding because of the scarcity of material data at elevated temperatures. Some simplifications and approximations are typically introduced to cope with this problem. These simplifications are necessary because of both lack of data and numerical problems when trying to model the actual high-temperature behavior of the material [32]. The material properties used here, are shown in Fig. 4. These data are taken from Lindgren [33]. In this figure, $\alpha$ is coefficient of linear thermal expansion, $\mathrm{c}$ is specific Heat, $\mathrm{E}$ is elastic modulus, $\mathrm{k}$ is thermal conductivity and $\sigma \mathrm{y}$ is yield stress. The filler metals are determine with help to Schaeffler Diagram [34] and was 308L.

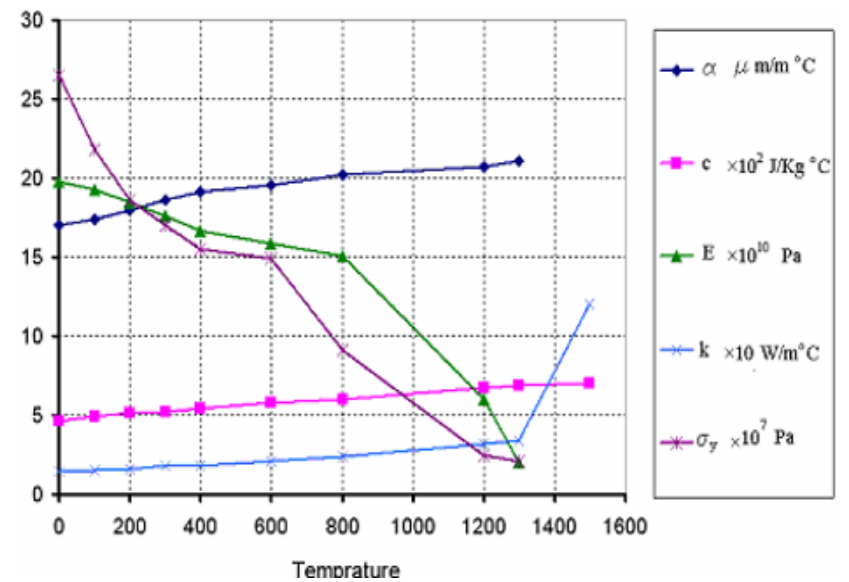

Fig. 4. Material properties used in this study [33].

\section{FINITE ELEMENT MODELING}

The problem is formulated as a successively coupled thermal stress analysis. First, a non-linear thermal analysis is performed to calculate the temperature history of the entire domain. Then, the results of the thermal analysis are applied as a thermal body load in a non-linear mechanical analysis to determine distortions. The finite element (FE) models for both thermal and structural analysis are the same. The general-purposed FE program ANSYS is used for the analyses. During the analysis a full Newton-Raphson iterative solution technique with direct sparse matrix solver is employed for obtaining a solution. During the thermal analysis, the temperature and the temperature dependent material properties alter very rapidly. Thus, a full Newton-Raphson technique with using modified material properties is believed to give more precise results.

A conventional technique named 'element birth and death' (which is extracted from Lindgren [35]) is used for modelling of the deposited weld. A complete FE model is generated in the start of the analysis. However, all elements representing the deposited weld except elements for the tack welds are deactivated by assigning them a very low stiffness. During the thermal analysis, all the nodes of deactivated elements (excluding those shared with the base metal) are also fixed at room temperature till the birth of the respective element. Deactivated elements are reactivated sequentially when they come under the effect of the welding torch. Linear elements are preferred than higher-order elements in non-linear problems of this type [36]. Here, eight-noded-brick elements with linear shape functions are used in the FE modeling. Only one half of the plate is modeled with assumption of symmetry. The basic FE model of plates is shown in Fig. 5. 


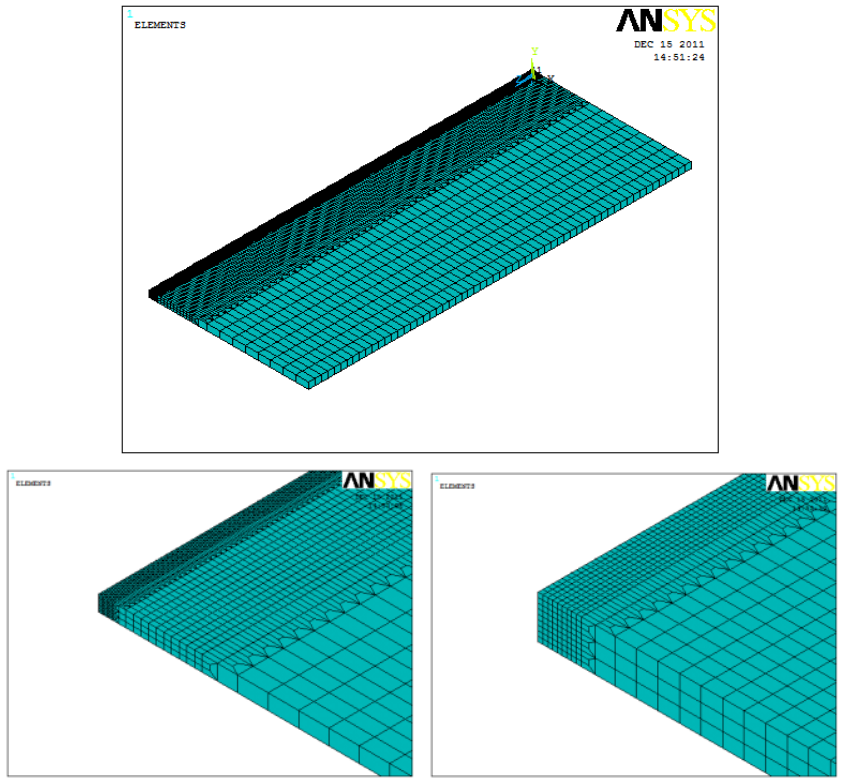

Fig. 5. Basic FE model.

\section{EXPERIMENTAL PROCEDURES}

\section{SAMPLE DESCRIPTION}

The materials tested (A240-TP304L) are commonly used for pressure vessel applications. Single pass butt-weld joint geometry with a back-weld pass and without root gap was used. Two $600 * 250 * 10 \mathrm{~mm}$ normalized A240-TP304L rolled plates were welded in V-groove ( $90^{\circ}$ included angle). Back-weld and the main weld-pass were performed by submerged arc welding (SAW) process. Two rectangular tension test specimens were extracted from Parent-Material (PM) to determine acoustoelastic constant.

\section{MEASUREMENT DEVICE}

The measurement device, shown in Fig. 6., includes an ultrasonic box with integrated pulser and receiver, computer and three normal transducers assembled on three wedges. A three-probe arrangement was used, with one sender and two receivers in order to eliminate environment temperature effect to the travel time. The nominal frequency and diameter of the piezoelectric elements are $2 \mathrm{MHz}$ and $6 \mathrm{~mm}$, respectively. Transducers were assembled on a united PMMA wedge. The ultrasonic box is a $100 \mathrm{MHz}$ ultrasonic testing device which has a synchronization between the pulser signal and the internal clock, that controls the $\mathrm{A} / \mathrm{D}$ converter. This allows very precise measurements of the time of flight - better than $1 \mathrm{~ns}$.

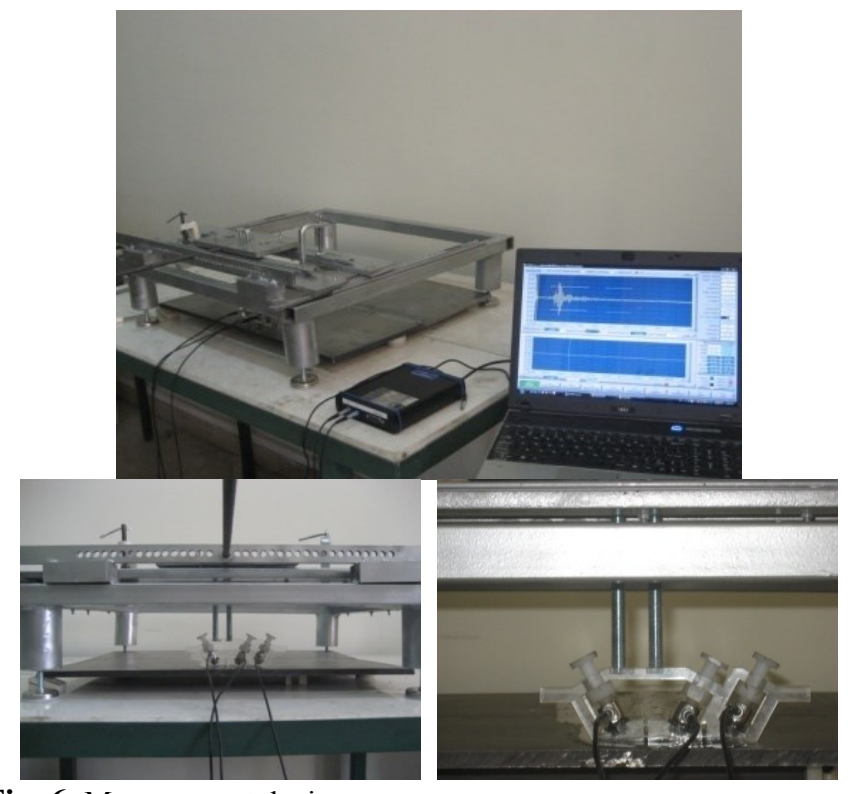

Fig. 6. Measurement devices.

\section{EVALUATION OF THE CALIBRATION CONSTANTS}

To evaluate the calibration constants (acoustoelastic constant, free stress time-of-flight), the calibration samples were taken in the direction parallel to the weld in order to avoid the texture effect. This direction also corresponds to that of the measured stress. Two rectangular tension test specimens were extracted from PM to determine acoustoelastic constant $\left(L_{11}\right)$ with average of results. To evaluate the residual stress from Equ.(4)., the value $t_{0}$ is measured directly from the stress-free samples and the acoustoelastic constant is deduced experimentally from a uniaxial tensile test associated with an ultrasonic measurement (Fig. 7.). Acoustoelastic constant represents the slope of the relative variation curve of the time-of-flight and the applied stress. (as shown in Fig. 8.)

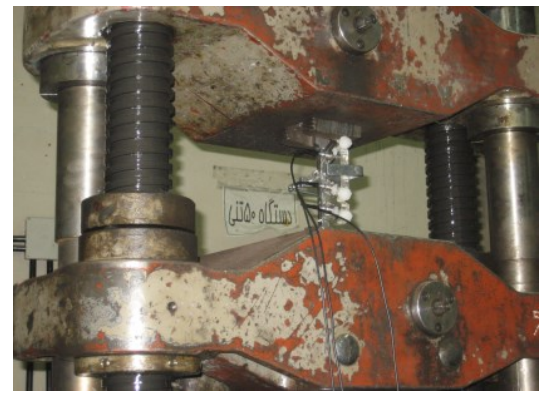


This is a peer-reviewed, accepted author manuscript of the following article: Javadi, Y., Raeisi, M. H., Pirzaman, H. S., \& Najafabadi, M. A. (2013). Using welding

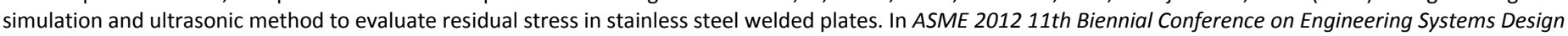
and Analysis, ESDA 2012 (Vol. 1, pp. 43-50). [ESDA2012-82637] New York: ASME. https://doi.org/10.1115/ESDA2012-82637

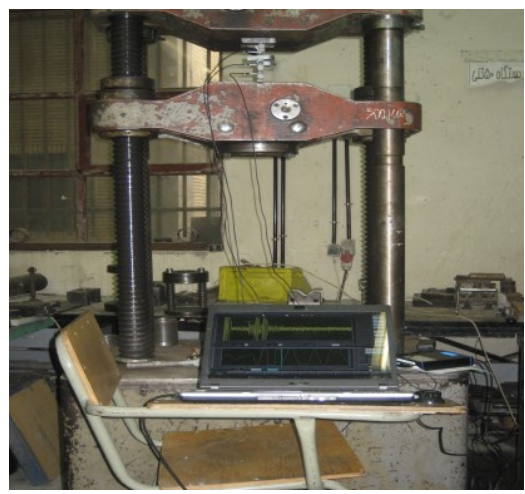

Fig. 7. Tensile test to evaluate acoustoelastic constant $\left(L_{11}\right)$.

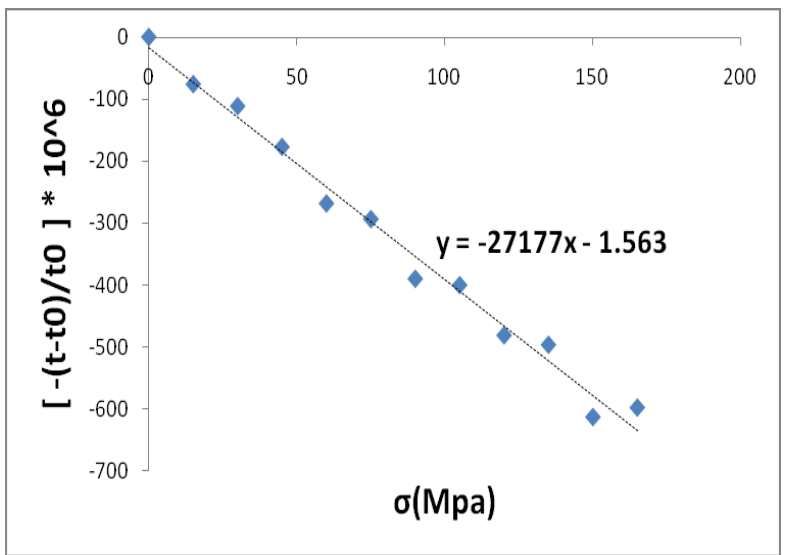

Fig. 8. Result of Tensile test to evaluate acoustoelastic constant.

\section{RESULTS AND DISCUSSION}

\section{ULTRASONIC DETERMINATION OF RESIDUAL STRESSES}

In this study, the ultrasonic measurement concerns the subsurface residual stresses. The measurements were parallel to the weld axis. The values of the residual stresses relating to each weld zone were calculated from the equations (1-4) and the results are shown in Fig. 9.

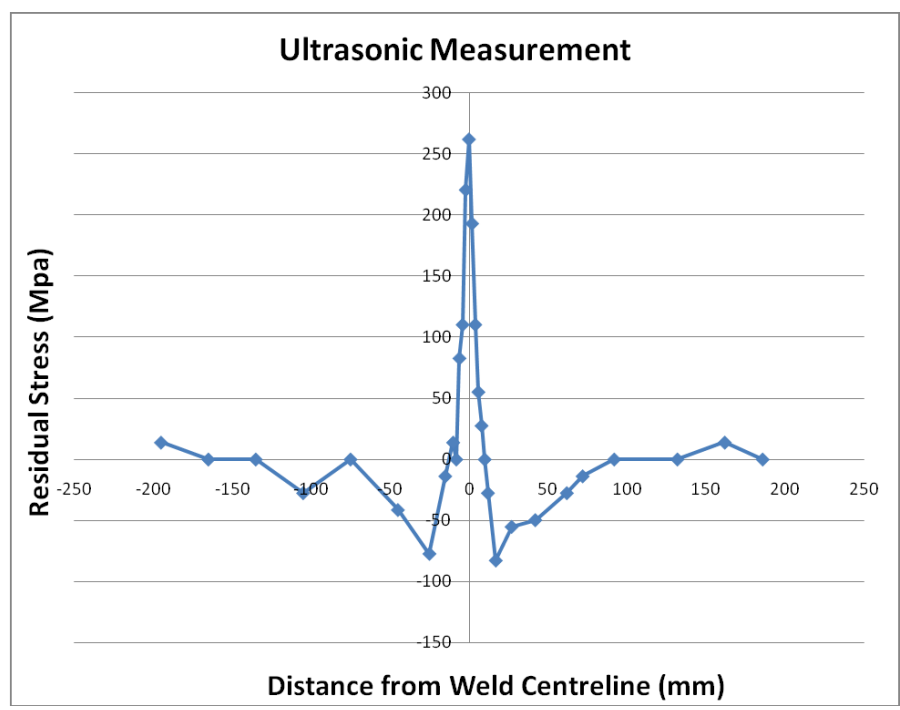

Fig. 9. Ultrasonic stress measurement results.

\section{FINITE ELEMENT DETERMINATION OF RESIDUAL STRESSES}

The FE model was run for welding process and its residual stresses were calculated for one side of the weld centerline with assumption of symmetry. The FE results are shown in Fig. 10.

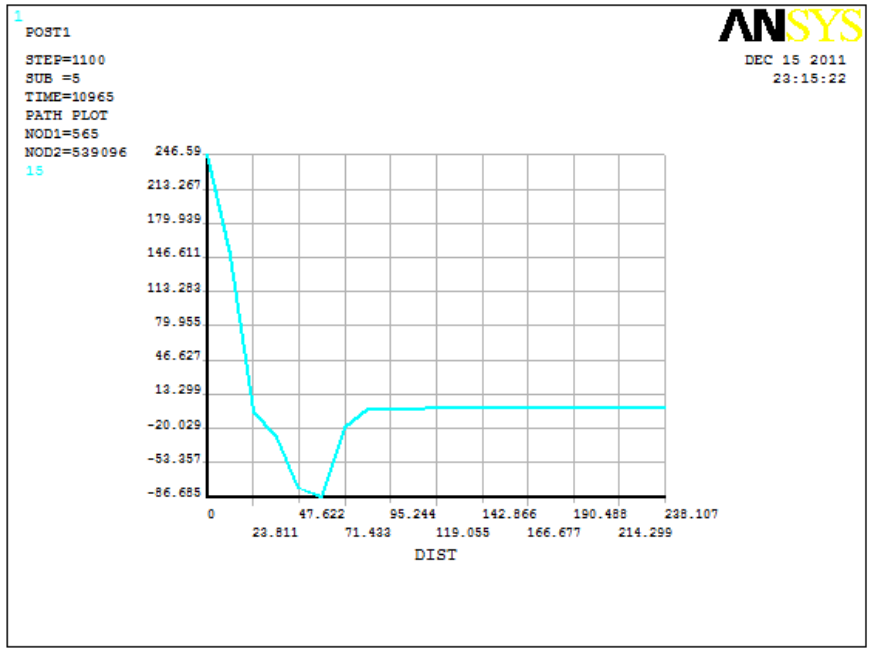

Fig. 10. Residual stress evaluation using Ansys finite element software.

\section{COMPARISON BETWEEN THE ULTRASONIC MEASUREMENT AND FINITE ELEMENT RESULTS}

Comparison between the ultrasonic measurement and finite element results was performed in order to validate the measurements. The results are shown in Fig. 11. 
This is a peer-reviewed, accepted author manuscript of the following article: Javadi, Y., Raeisi, M. H., Pirzaman, H. S., \& Najafabadi, M. A. (2013). Using welding

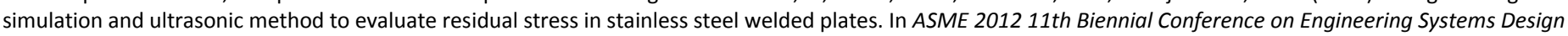
and Analysis, ESDA 2012 (Vol. 1, pp. 43-50). [ESDA2012-82637] New York: ASME. https://doi.org/10.1115/ESDA2012-82637

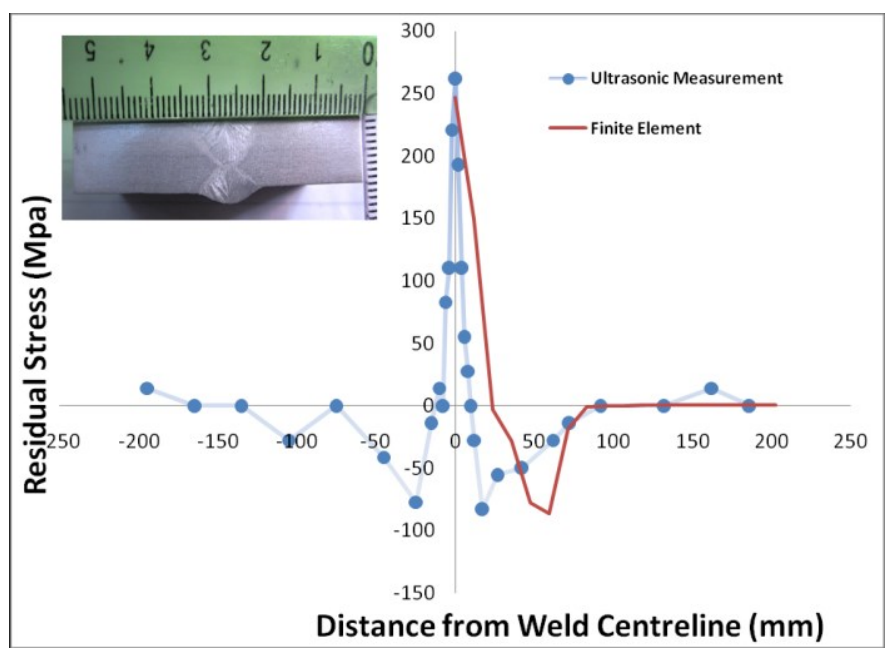

Fig. 11. Comparison between the Finite Element and Ultrasonic stress measurement.

From Fig. 11. it can be concluded that:

1. Finite Element results were in reasonable agreement with ultrasonic measurements in the weld zone and parentmetal. But ultrasonic method had a wrong prediction of residual stresses in the HAZ (heat affected zone) because of complicated microstructure of this region. In this zone, difference between ultrasonic and $\mathrm{FE}$ is due to the microstructure effect, since PM calibration constants were used instead of the HAZ constant. To get a good results in the HAZ, reproducing the microstructure of this zone using a specific heat treatment mentioned in Qozam et al.[37] is required.

2. Combining finite element with ultrasonic stress measurement $\left(\mathrm{FEL}_{\mathrm{CR}}\right)$ in the welding process has been studied here. Advantages of this combination are:

a. Predicting exact dimensions of welding regions (Parent-metal, HAZ and Weld-zone) by finite element and use it to exactly determine tensile strength samples for evaluating acoustoelastic constants.

b. Have a good knowledge of bulk stresses by finite element analysis and use it to verify $L_{C R}$ capability of bulk stress measurement.

c. Research documentations in finite element is more than ultrasonic stress measurement so it can be said that FE can be supplement of ultrasonic stress measurement especially in the absent of the other experimental stress measurement methods.

\section{CONCLUSION}

This paper confirms the potential of the FEL $_{\mathrm{CR}}$ (which has been introduced here) to accurately evaluate the welding residual stresses. FEL $\mathrm{CR}_{\mathrm{C}}$ can be developed and will work better if:

1- Tensile strength samples are extracted from all of the welding zones.

2- Microstructure effects are not neglected in welding simulation.

3- Hole-Drilling or the other experimental stress measurement methods are used to verify FE.

\section{REFERENCES}

1. N. Grayli, JC. Shyne, Effect of microstructure and prior austenite grain size on acoustic velocity and attenuation in steel, Rev Prog NDE, 4(B)(1985), pp. 927-936.

2. R. Herzer, E. Schneider, Instrument for the automated ultrasonic time-of-flight measurement a tool for materials characterization, Springer, 1989, pp. 673-680.

3. P. Palanchamy, A. Joseph, T. Jayakumar, Ultrasonic velocity measurements for estimation of grain size in austenitic stainless steel, NDT E Int, 28(1995), pp. 179185.

4. EP. Papadakis, Physical acoustics and microstructure of iron alloys, Int Mater Rev, 29(1984), pp. 1-24.

5. C. Hakan Gür, B. Orkun Tuncer, Nondestructive investigation of the effect of quenching and tempering on medium-carbon low alloy steels, Int J Microstruct Mater Prop, 1(2005), pp. 51-60.

6. MA. Ploix, R. El Guerjouma, J. Moysan, G. Corneloup, B. Chassignole, Acoustical characterization of austenitic stainless-steel welds for experimental and modeling, NDT. J Soc Adv Sci, 17(2005), pp. 76-81.

7. M. Spies, E. Schneider, Non-destructive analysis of texture in rolled sheets by ultrasonic techniques, Text Microstruct, 12(1990), pp. 219-213.

8. GC. Johnson, Acoustoelastic response of a polycrystalline aggregate with orthotropic texture, J Appl Mech, 52(1985), pp. 659-663.

9. CM. Sayers, Ultrasonic velocities in anisotropic polycrystalline aggregates, J Phys D Appl Phys, 15(1982), pp. 2157-2167.

10. C. Hakan Gür, İ. Çam, Comparison of magnetic Barkhausen noise and ultrasonic velocity measurements for microstructure evaluation of SAE 1040 and SAE 4140 steels, Materials Charact, 58(2007), pp. 447-454C.

11. YH. Nam, YI. Kim, SH. Nahm, Evaluation of fracture appearance transition temperature to forged 3Cr-1Mo$0.25 \mathrm{~V}$ steel using ultrasonic characteristics, Mater Lett., 60(2006), pp. 3577-3581.

12. JH. Cantrell, K. Salama, Acoustoelastic characterization of materials, Int Mater Rev, 36(1991), pp. 125-145. 
This is a peer-reviewed, accepted author manuscript of the following article: Javadi, Y., Raeisi, M. H., Pirzaman, H. S., \& Najafabadi, M. A. (2013). Using welding

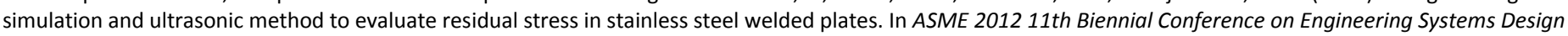
and Analysis, ESDA 2012 (Vol. 1, pp. 43-50). [ESDA2012-82637] New York: ASME. https://doi.org/10.1115/ESDA2012-82637

13. K. Salama, Relationship between temperature dependence of ultrasonic velocity and stress, Quantitative nondestructive evaluation, 1985, pp. 1109-1119

14. H. Mohbacher, E. Schneider, K. Goebbels, Temperature dependence of third-order elastic constants, Proc 9th international conference on experimental mechanics, 3(1990), pp. 1189-1197.

15. DI. Crecraft, The measurement of applied and residual stresses in metals using ultrasonic waves, J Sound Vib., 5(1967), pp. 173-192.

16. A. Lhémery, P. Calmon, S. Chatillon, N. Gengembre, Modeling of ultrasonic fields radiated by contact transducer in a component of irregular surface, Ultrasonics, 40(2002), pp. 231-236.

17. A. P. Chakravati, L. M. Malik, J. A. Goldak, Prediction of Distortion and Residual Stresses in Panel Welds, Computer modelling of fabrication processes and constitutive behaviour of metals, 1986, pp. 547-561.

18. J. Goldak and M. Bibby, Computational Thermal Analysis of Welds, Modeling of Casting and Welding Processes, 4(1988), pp. 153-166.

19. H. Hibbit, P. V. Marcal, A Numerical, Thermo-Mechanical Model for the Welding and Subsequent Loading of a Fabricated Structure, Computers \& Structures, 3(1973), pp. 1145-1174.

20. J. H. Argyris, J. Szimmat, and K. J. Willam, Computational Aspects of Welding Stress Analysis, Computer Methods in Applied Mechanics and Engineering, 33(1982), pp. 635-666.

21. E. F. Rybicki, D. W. Schmueser, R. B. Stonesifer, J. J. Groom, and H. W. Mishler, A Finite-Element Model for Residual Stresses and Deflections in Girth-Butt Welded Pipes, Journal of Pressure Vessel Technology, 100(1978), pp. 256-262.

22. V.J Papazoglou and K. Masubuchi, Numerical Analysis of Thermal Stresses during Welding including Phase Transformation Effects, Journal of Pressure Vessel Technology, 104(1982), pp. 198-203.

23. Y. Ueda, KH. Murakawa, N.X. Ma and H. Maeda, FEM Analysis of 3-D Welding Residual Stresses and Angular Distortion in T-type Fillet Welds, Transactions of JWRI, 24(1995), pp. 115-122.

24. D.M. Egle, D.E. Bray, Measurement of acoustoelastic and third order elastic constants for rail steel, J. Acoust. Soc. Am, 60(1976), pp. 741-744.

25. D.E. Bray, R.K. Stanley, Nondestructive Evaluation, CRC Press, Boca Raton, FL revised edition, 1997.

26. L.M. Brekhovskii, Waves in Layered Media, Academic Press, 1(1960).
27. L.V. Basatskaya, I.N. Ermolov, Theoretical study of ultrasonic longitudinal subsurface waves in solid media, 1980.

28. P. Junghans, D.E. Bray, Beam characteristics of high angle longitudinal wave probes, In: R.N. Pangbom, 1991.

29. K.J. Langenberg, P. Fellenger, R. Marklein, On the nature of the so-called subsurface longitudinal wave and/or the surface longitudinal 'creeping'wave, Res. Nondest. Eval., 2(1990), pp. 59-81.

30. D.E. Bray, W. Tang, Evaluation of Stress Gradients in Steel Plates and Bars with the $L_{C R}$ Ultrasonic Wave, Nuclear Engineering and Design, 207(2001), pp. 231-240.

31. J.Goldak, M.Akhlaghi, Computational Welding Mechanics, Springer, 2005.

32. LE. Lindgren, Finite element modelling and simulation of welding part 2: improved material modeling, J Thermal Stress, 24(2001), pp. 195-231.

33. LE. Lindgren, R. Hedblom, Modelling of addition of filler material in large deformation analysis of multipass welding, Commun Numer Methods Eng, 17(2001), pp. 647-57.

34. A. Schaeffler, Constitution diagram for stainless steel weld metal, Metal Progress, 1949, pp. 680-680.

35. LE. Lindgren, Finite Element Modelling and Simulation of Welding Part 1: Increased complexity, J Thermal Stress, 24(2001), pp. 141-92.

36. D. Deng, H. Murakawa, Numerical simulation of temperature field and residual stress in multi-pass welds in stainless steel pipe and comparison with experimental measurements, Computational Materials Science, 37(2006), pp. 269-277.

37. H. Qozam, S. Chaki, G. Bourse, C. Robin, H. Walaszek and P. Bouteille, Microstructure Effect on the $L_{C R}$ Elastic Wave for Welding Residual Stress Measurement, Experimental Mechanics, 50(2010), pp. 179-185. 